\title{
A Novel Method for the Selective Identification of Metformin in Bulk and Pharmaceutical Formulations Using Sodium Nitroprusside as a Chromogenic Reagent by Spectrophotometry
}

\author{
SHIVAJI R. LABHADE ${ }^{1 *}$, KAILAS R. LABHADE ${ }^{2}$ and VISHWAS B. GAIKWAD ${ }^{3}$ \\ ${ }^{1}$ Department of Chemistry, K. T. H. M. College, Gangapur Road, Shivajinagar, \\ Nashik- 422002, India \\ ${ }^{2}$ Department of Chemistry, S.V.K.T. Arts, Science and Commerce College, Deolali Camp, \\ Nashik- 422401, India \\ ${ }^{3}$ Director, BCUD, University of Pune, Ganeshkhind, Pune-411007, Maharashtra State, India \\ srlabhade3571@rediffmail.com
}

Received 20 July 2014 / Accepted 18 August 2014

\begin{abstract}
A novel method to identify the metformin with a good selectivity has been established by using sodium nitroprusside as a chromogenic reagent. The experiment indicates that in basic solution sodium nitroprusside can react with the oxidized product (obtained by the action of sodium hypochlorite) of metformin to form a green colored 1,3 dinitrosyl- $N$ '-(iminomethyl)- $N, N$-dimethyl formamidine with maximum absorption at $680 \mathrm{~nm}$. The test when compared with blank is sensitive for spectrophotometric detection of metformin up to $16.56 \mu \mathrm{g}$ in $10 \mathrm{~mL}$ solution. The reaction stoichiometric ratio of the oxidized product of metformin to sodium nitroprusside is $1: 2$. The reaction mechanism of the green product is discussed in present investigation. The proposed method has been successfully applied for identification of metformin in aqueous solution containing glibenclamide, glimepiride, glipizide and gliclazide. Because of the dissociative nature of the green colored product, for a large linear range of microgram concentration of metformin the absorbance of the green colored product is not found to be linear. Hence it can concluded from this analysis that sodium nitroprusside is not suitable chromogenic reagent for spectrophotometric determination of metformin in aqueous solution.
\end{abstract}

Keywords: Metformin, Metformin Identification, Sodium Nitroprusside, Sodium Hypochlorite

\section{Introduction}

Metformin is an oral antihyperglycemic agent used to lower blood glucose in patients suffering from non-insulin dependent diabetics mellitis ${ }^{1}$. Chemically metformin is $\mathrm{N}, \mathrm{N}$ dimethylimidodicarbonimidic diamide hydrochloride ${ }^{2}$ with molecular weight $165.62 \mathrm{~g} / \mathrm{mol}$.

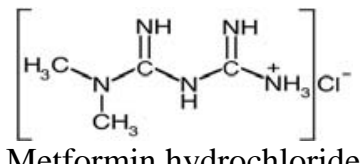

Metformin hydrochloride 
Spectrophotometry is the most common and convenient analytical tool due to its inherent simplicity and low costing. Thus is used in most of the quality control and clinical laboratories. Literature survey indicates that several spectrophotometric methods are used for determination of metformin. These includes direct determination with multivariate calibration technique ${ }^{3}$, reaction of metformin with cupric ion and cyclohexylamine in basic medium $^{4}$, formation of oxidative coupling of the reaction product of metformin with 1naphthol ${ }^{5}$, oxidation of metformin yellow-colored chromophore ${ }^{6}$, formation of charge transfer complex of metformin with iodine in acetonitrile medium ${ }^{7}$ as well as determination with the first-derivative method $^{8-9}$. There is no any visible spectrophotometric method yet reported for quantitation of metformin using sodium nitroprusside. The aim of this study was to develop a new spectrophotometric method for quantitative determination of metformin as a raw material and in some pharmaceutical preparations with no interference of other constituents in their formulations.

Sodium pentacyanonitrosylferrate(II) or sodium nitroprusside (SNP), $\mathrm{Na}_{2}\left[\mathrm{Fe}(\mathrm{CN})_{5} \mathrm{NO}\right]$ is a popular derivatization agent of analytically important for the detection and determination of wide variety of nucleophilic moieties such as primary or secondary aliphatic amines, aldoximes, ketones, nitrites, phenols, pyrroles, quinones, thiols, thioureas and uracils ${ }^{10-11}$. Many spectrophotometric methods adapted SNP as an analytical reagent in their applications, including the assays of Rosoxacin ${ }^{12}$, Paracetamol $^{13}$, Streptomycin ${ }^{14}$, Meloxicam $^{15}$, Cefradine ${ }^{16}$, Diosmin ${ }^{17}$, Atenolol ${ }^{18}$, Methanol $^{19}$, Piroxicam ${ }^{20}$, Sumatriptan succinate $^{21}$, Ramipril ${ }^{22}$ and Thiosulphate ${ }^{23}$. Furthermore, the techniques like high performance liquid chromatography ${ }^{24}$ and flow injection analysis ${ }^{25}$ have also adapted SNP as an analytical reagent in their applications. In addition, the coupling reaction of SNP with the diazotized $p$-nitroaniline in basic solution also been used for spectrophotometric determination of sodium nitroprusside ${ }^{26}$. For detection of impurities ${ }^{27}$ with TLC technique, the mixture of SNP, potassium ferrocyanide and sodium hydroxide has been employed for identification of metformin. It has an added advantage that the test does not involved oxidation of metformin by sodium hypochlorite solution. Spectrophotometric determinations of metformin ${ }^{5-6}$ and paracetamol ${ }^{28}$ have been utilized sodium hypochlorite used as oxidizing reagent for oxidation of both the analytes. It has been reported that using sodium hypochlorite solution, metformin is oxidized to its $\beta$-diketone ${ }^{6}$ product which subsequently reacts with SNP in basic solution. Due to nucleophilic reactivity of oxygen atoms of the $\beta$ diketone of metformin with electrophilic nitrosyl group in two SNP molecules, a green colored 1, 3 dinitrosyl- $N$ '-(iminomethyl)- $N, N$-dimethyl formamidine complex is formed. Because of dissociative nature of this reaction product we were unable to develop a method for quantitative determination of metformin. But using SNP as chromogenic reagent same experiment gives a novel method for selective identification of metformin in aqueous solution containing glibenclamide, glimepiride, glipizide and gliclazide is discussed in this paper.

\section{Experimental}

Shimadzu UV-1800 double beam UV-Vis spectrophotometer with software UVProbe 2.33 using $10 \mathrm{~mm}$ quartz silica cells was used for all spectral measurements.

\section{Reagents}

All the chemicals used were of analytical grade and so used without further purification. Distilled water was used for diluting the standard, reagents and samples. All the prepared reagents were stored in the amber colored bottles and protected from direct sunlight. 


\section{Sodium hypochlorite ( $\mathrm{NaOCl}$ ) solution}

A $0.2 \%$ solution was prepared by diluting $25.0 \mathrm{~mL}$ of $4 \%$ solution of commercially available sodium hypochlorite to $500 \mathrm{~mL}$ with distilled water and stored in amber colored bottle with air tight stopper.

\section{Sodium nitroprusside (SNP) solution}

A $2.0 \times 10^{-2} \mathrm{~mol} \mathrm{~L}^{-1}$ solution was prepared by dissolving $2.980 \mathrm{~g}$ of $\mathrm{Na}_{2}\left[\mathrm{Fe}(\mathrm{CN})_{5} \mathrm{NO}\right] .2 \mathrm{H}_{2} \mathrm{O}$ in $500 \mathrm{~mL}$ of distilled water.

\section{Sodium hydroxide $(\mathrm{NaOH})$ solution}

A $1.0 \mathrm{~mol} \mathrm{~L}^{-1}$ solution was prepared by dissolving $20.0 \mathrm{~g}$ of $\mathrm{NaOH}$ in $500 \mathrm{~mL}$ of distilled water.

\section{Standard metformin hydrochloride $(\mathrm{MHCl})$ solution}

A $1.0 \times 10^{-3} \mathrm{~mol} \mathrm{~L}^{-1}$ of $\mathrm{MHCl}$ solution was prepared by dissolving $82.81 \mathrm{mg}$ of pharmaceutical grade $\mathrm{MHCl}\left(\mathrm{C}_{4} \mathrm{H}_{11} \mathrm{~N}_{5} \mathrm{HCl}, 165.62 \mathrm{~g} \mathrm{~mol}^{-1}\right)$ in $500 \mathrm{~mL}$ of distilled water.

\section{Dosage forms}

Tab. Metfor (500 mg MHCl), Tab. Glycomet (500 mg MHCl), Tab. Glycinorm (80 mg gliclazide), Tab. Daonil (5 mg glibenclamide), Tab. Glimestar (1 mg glimepiride) and Tab. Glyzip (5 mg glipizide)

\section{General Analytical Procedure}

\section{Caution}

Potentially hazardous volatile gasses were possibly evolved during the experimentation. Preparation of solutions of metformin with sodium hypochlorite and sodium nitroprusside was done in a fuming hood. Absorbance measurement was carried out in a well ventilated area.

Aliquots of $5.0 \mathrm{~mL}$ of aqueous solution of $\mathrm{MHCl}$ containing 16.56-82.80 $\mu \mathrm{g}$ of $\mathrm{MHCl}$ were transferred to $50 \mathrm{~mL}$ beakers containing $2.0 \mathrm{~mL}$ of $1.0 \mathrm{~mol} \mathrm{~L}^{-1} \mathrm{NaOH}$ solution. Then $1.0 \mathrm{~mL}$ of $0.2 \% \mathrm{NaOCl}$ solution and $2.0 \mathrm{~mL}$ of $5.0 \times 10^{-3} \mathrm{~mol} \mathrm{~L}^{-1}$ of SNP solution were added. In absence of direct sunlight the reaction mixtures were made to react at room temperature for 2 minutes. Later, according to the sequential addition of SNP reagent, the absorbance of the green colored complex was instantaneously measured at $680 \mathrm{~nm}$ against reagent blank. The increase in absorbance of the test solution with respect to blank indicates presence of metformin in the solution. For test solution having concentration of $\mathrm{MHCl}$ greater than and equal to $49.68 \mu \mathrm{g}$, the green color thus produced by this reaction was noticeable without instrument. The green color obtained only in strongly basic solution and found to be completely vanished when solution was made neural or acidic.

\section{Results and Discussion}

The aim of this work is to establish a simple, sensitive, reliable, selective and cheap spectrophotometric method for the identification of metformin drug in pure form and in its pharmaceutical formulations.

\section{Reaction mechanism and reaction stoichiometry}

The developed method is based on reaction of metformin with the sodium hypochlorite and SNP reagents in basic solution. Addition of sodium hypochlorite to the alkaline solution of metformin hydrochloride yields $\beta$-diketone ${ }^{6}$, an oxidized product of the metformin. Sodium 
nitroprusside can react with many nucleophilic agents in basic solution and form the colored derivative due to electrophilic reactivity of its nitrosyl group ${ }^{10-11}$. Similarly, in basic medium the oxygen atoms of $\beta$-diketone molecule of metformin have nucleophilicity and trend to attack on the electron deficiency center in nitrosyl groups of two SNP molecules to give 1, 3 dinitrosyl- $N$ '-(iminomethyl)- $N, N$-dimethyl formamidine compound. It was proved by varying the concentration of metformin and SNP, the stoichiometric ratio of reaction between $\beta$-diketone of the metformin and SNP is $1: 2$. It is presumed that both the oxygen of the $\beta$-diketone of metformin reacts with nitrosyl groups. Hence, it seems reasonable that the reaction mechanism is as follows (Scheme 1):

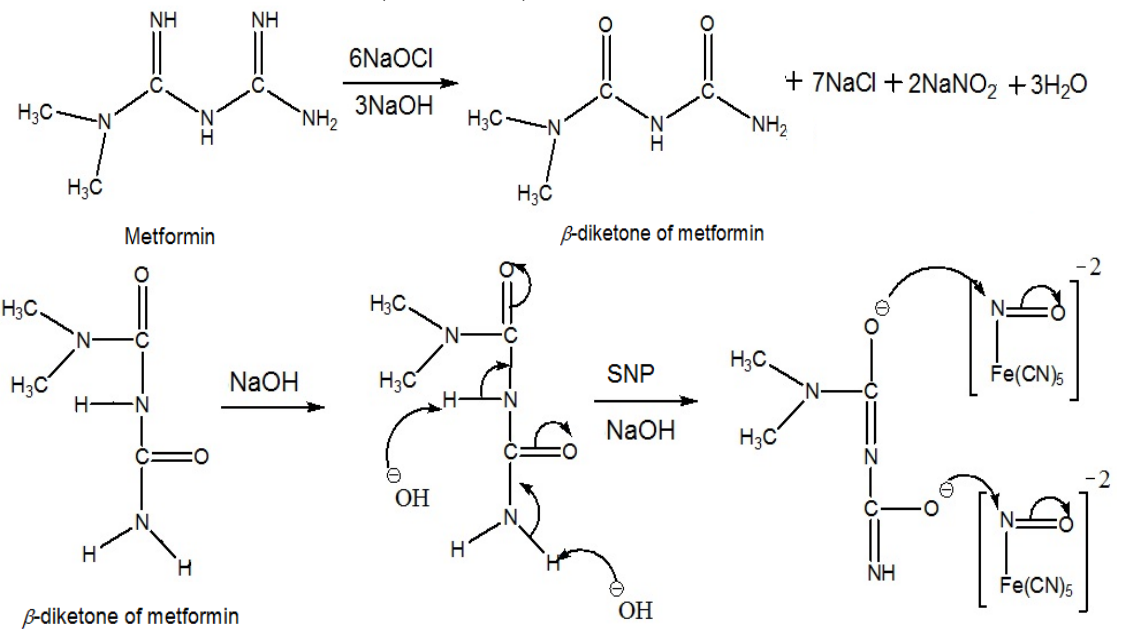

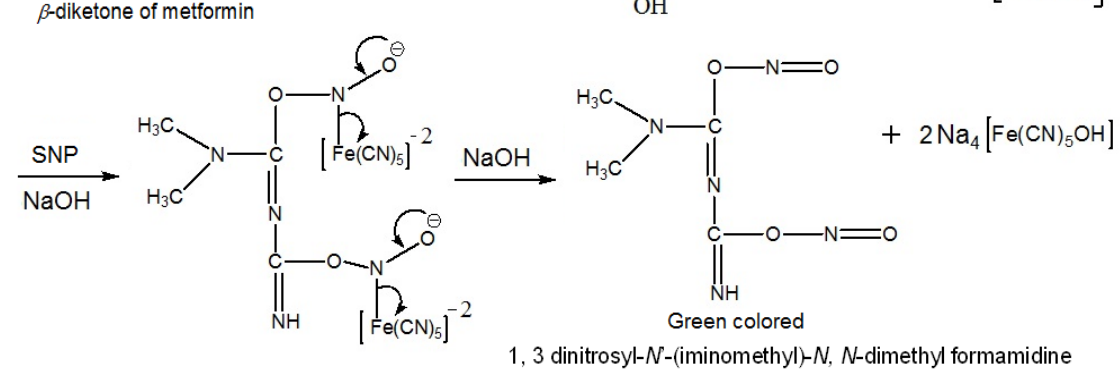

Scheme 1. Reaction mechanism

The reaction reported for determination of paracetamol ${ }^{13}$ illustrate that, paracetamol molecule linked with nitrosyl group through phenolic oxygen gives green colored compound with absorption maxima at $700 \mathrm{~nm}$. Similarly, $\beta$-diketone of metformin reacts with two nitrosyl groups of two SNP molecules through the two oxygen atoms also gives the green color to the product because of the oxygen-nitrosyl group linkages. The order of addition of reagents affects the results of identification of metformin. The order used in the proposed method was aqueous solutions of metformin, sodium hypochlorite and SNP. Without pre-reaction by sodium hypochlorite solution metformin does not give the green color with sodium nitroprusside.

\section{Selection of wavelength}

This 1,3 dinitrosyl- $N$ '-(iminomethyl)- $N, N$-dimethyl formamidine complex of $\beta$-diketone of metformin exhibits an absorption spectrum as shown in Figure 1 with maximum absorption at $680 \mathrm{~nm}$. The existence of peak at $680 \mathrm{~nm}$ for the colored product is attributed to the 
bathochromic shift because of increase in conjugation in the $\beta$-diketone molecule due to substitution of two nitrosyl groups. The $\beta$-diketone of metformin showed inertness towards the potassium ferrocyanide consequently cyanide ligand of the nitroprusside anion does not react with $\beta$-diketone anion.

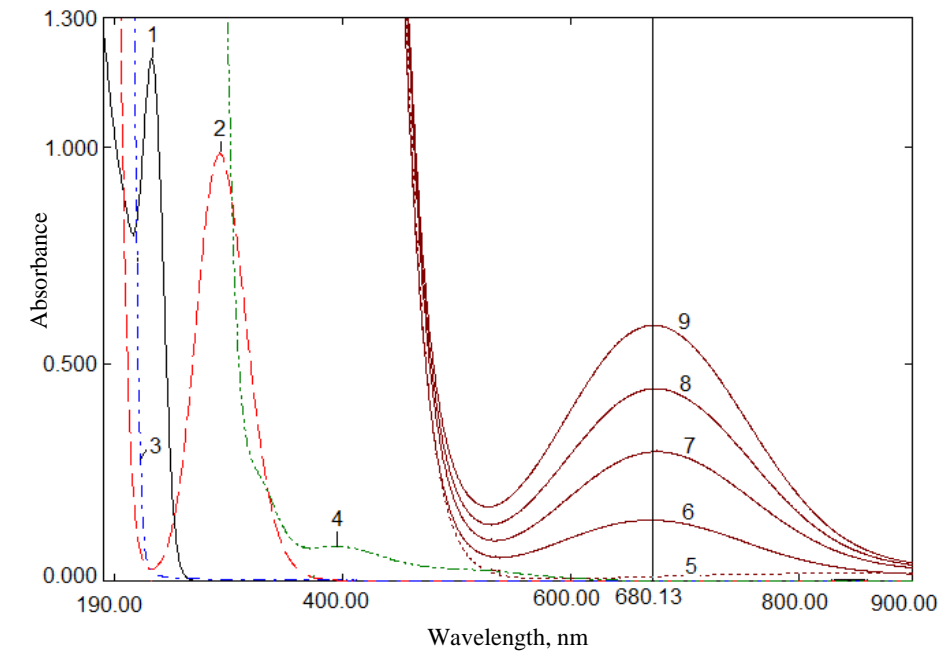

Figure 1. Absorption spectra (obtained against distilled water) at $10 \mathrm{~mL}$ dilution of $2.0 \mathrm{~mL}$ of $0.5 \times 10^{-3} \mathrm{~mol} \mathrm{~L}^{-1}$ of pure $\mathrm{MHCl}(1)$ of $1.0 \mathrm{~mL}$ of $0.2 \%$ pure $\mathrm{NaOCl}$ solution (2) of 2.0 $\mathrm{mL}$ of $1.0 \mathrm{~mol} \mathrm{~L}^{-1}$ of $\mathrm{NaOH}(3)$ of $2.0 \mathrm{~mL}$ of $2.0 \times 10^{-2} \mathrm{~mol} \mathrm{~L}^{-1}$ of pure SNP (4) and of 0.0 , 1.0, 2.0, 3.0 and $4.0 \mathrm{~mL}$ of $0.5 \times 10^{-3} \mathrm{~mol} \mathrm{~L}^{-1}$ of $\mathrm{MHCl}(5-9)$ added to $2.0 \mathrm{~mL}$ of $1.0 \mathrm{~mol} \mathrm{~L}^{-1}$, $1.0 \mathrm{~mL}$ of $1 \% \mathrm{NaOCl}$ of $\mathrm{NaOH}$ and $2.0 \mathrm{~mL}$ of $2.0 \times 10^{-2} \mathrm{~mol} \mathrm{~L}^{-1}$ of SNP.

Aqueous solution of $\mathrm{MHCl}, \mathrm{NaOCl}, \mathrm{NaOH}$, and SNP does not show absorbance at the wavelength at which 1, 3 dinitrosyl- $N$ '-(iminomethyl)- $N, N$-dimethyl formamidine complex of $\beta$-diketone of metformin exhibits maximum absorption. Consequently, the spectral region 650 to $750 \mathrm{~nm}$ was found to be appropriate for detection of metformin through the absorbance measurement. The wavelength of maximum absorption $(\lambda$-max) of the green colored product and its color intensity were found fluctuated with the concentrations of metformin and SNP. For lower concentration of metformin as well as sodium nitroprusside, the absorption maximum was found shifted to longer wavelength.

\section{Color stability of the product}

Aqueous solution of metformin after reaction with $\mathrm{NaOCl}$, SNP in $\mathrm{NaOH}$ produces a green colored derivative product of the $\beta$-diketone of metformin. The absorbance of the formed product was measured at different time interval. It was found that color intensity of the green colored product was found to be gradually increasing to maximum within the time span of 2 to 3 minutes and thereafter decreasing to minimum as shown in Figure 2.

Under the recommended conditions, there is a linear relationship between the absorbance and the concentration of metformin. For different solutions having microgram concentration of metformin, absorbance of the green colored product is not linear with the concentration of metformin because of the uneven time span in addition of SNP reagent and measurement of the absorbance. Because of dissociative nature of the reaction product, the absorbance of the same solution when measured at different time interval produces different 
absorbance readings. Consequently, the time span laps in between the absorbance measurement of a series of solutions produces non-linear relation between absorbance and concentration of metformin. Therefore, the procedure was not found suitable for quantitative determination of metformin in aqueous medium.

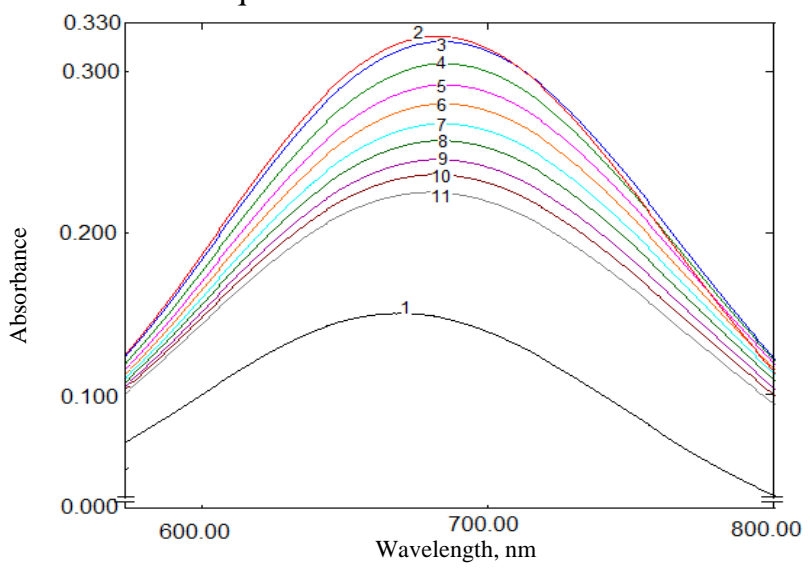

Figure 2. Absorption spectra (obtained against reagent blank) at $10 \mathrm{~mL}$ dilution of $3.0 \mathrm{~mL}$ of $0.25 \times 10^{-3} \mathrm{~mol} \mathrm{~L}^{-1}$ of pure $\mathrm{MHCl}$ added to $2.0 \mathrm{~mL}$ of $1.0 \mathrm{~mol} \mathrm{~L}^{-1}$ of $\mathrm{NaOH}, 1.0 \mathrm{~mL}$ of $1 \%$ $\mathrm{NaOCl}$, and $3.0 \mathrm{~mL}$ of $5.0 \times 10^{-3} \mathrm{~mol} \mathrm{~L}^{-1}$ of SNP. After addition of SNP reagent, the curves 1 to 11 were obtained at $1,3,5,7,9,11,13,15,17,19$ and 21 minutes respectively.

\section{Sensitivity of detection}

The procedure is suitable for detection of metformin hydrochloride in aqueous solution up to concentration of $16.56 \mu \mathrm{g}$ at $10 \mathrm{~mL}$ dilution. Figure 3 illustrates that reagent blank solution is transparent at the wavelength of analysis. The test solution containing metformin showed increase in absorbance. For low concentration of metformin, the absorbance was found negligible and detection of metformin in the solution was found only by spectrophotometer. But solutions having concentration of metformin greater than and equal to $49.68 \mu \mathrm{g}$ showed distinct visible green color and detection of metformin was feasible without spectrophotometer.

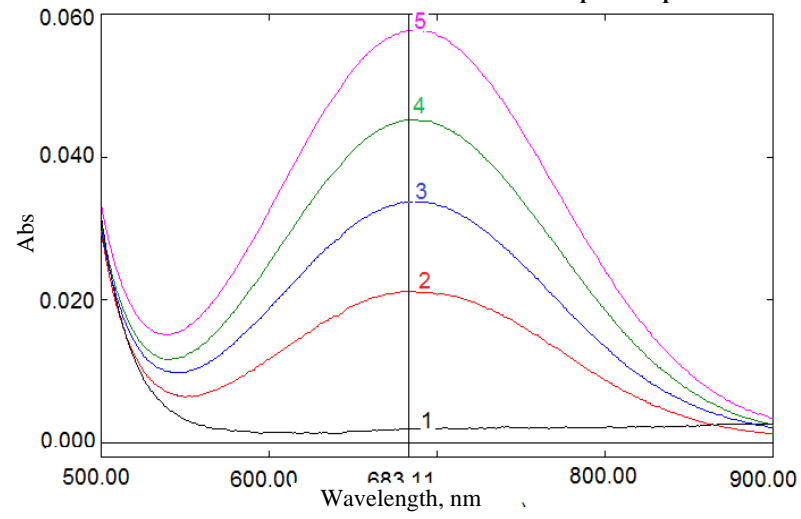

Figure 3. Absorption spectra (obtained against distilled water) at $10 \mathrm{~mL}$ dilution of 0.0 , 16.56, 33.12, 49.68 and $66.24 \mu \mathrm{g}$ of $\mathrm{MHCl}(1-5)$ added to $2.0 \mathrm{~mL}$ of $1.0 \mathrm{~mol} \mathrm{~L}^{-1}$ of $\mathrm{NaOH}$, $1.0 \mathrm{~mL}$ of $0.2 \% \mathrm{NaOCl}$, and $2.0 \mathrm{~mL}$ of $5.0 \times 10^{-3} \mathrm{~mol} \mathrm{~L}^{-1}$ of SNP. 


\section{Interference study in detection of metformin}

The effect of ingredients commonly found in metformin formulations was studied by the identification of metformin with the addition of ingredients. The commercially available dosage forms of metformin ${ }^{29}$ contain pure metformin and includes Metfor and Glycomet tablets each with $500 \mathrm{mg} \mathrm{MHCl}$. In addition to this dosage forms of the metformin is also available in combination with glibenclamide (Tab. Diabetrol: $500 \mathrm{mg} \mathrm{MHCl}+5 \mathrm{mg}$ glibenclamide), gliclazide (Tab. Reclimate: $500 \mathrm{mg} \mathrm{MHCl}+80 \mathrm{mg}$ gliclazide), glipizide (Tab. Actizide-M: 500 mg MHCl + 5 mg glipizide), glimepiride (Tab. Gemer 1: 500 mg MHCl $+1 \mathrm{mg}$ glimepiride), etc. In order to study the interfering role of glibenclamide, gliclazide, glipizide and glimepiride in metformin detection, the alkaline solutions of the tablet Daonil (5 mg glibenclamide), Glycinorm (80 mg gliclazide), Glyzip (5 mg glipizide), and Glimestar (1 mg glimepiride) were tested by above reaction. The solution of each single tablet was prepared separately in $25.0 \mathrm{~mL}$ of $1.0 \mathrm{~mol} \mathrm{~L}^{-1}$ of $\mathrm{NaOH}$ and after filtration through Whatman filter paper, $2.0 \mathrm{~mL}$ of solution of each tablet was tested by above recommended procedure. It was observed that none of the above mentioned in alkaline solution could produce green color made to react with sodium hypochlorite and sodium nitroprusside. The absorption spectra Figure 4, illustrates that reaction products of glibenclamide, glimepiride, glipizide, gliclazide obtained with sodium hypochlorite and sodium nitroprusside in basic medium are transparent at the wavelength of analysis. Furthermore, the interference of four tablets was also tested by same procedure with their dissolution in $25.0 \mathrm{~mL}$ of $95 \%$ ethanol. It was noted that all tablets showed negative test with sodium hypochlorite and sodium nitroprusside.

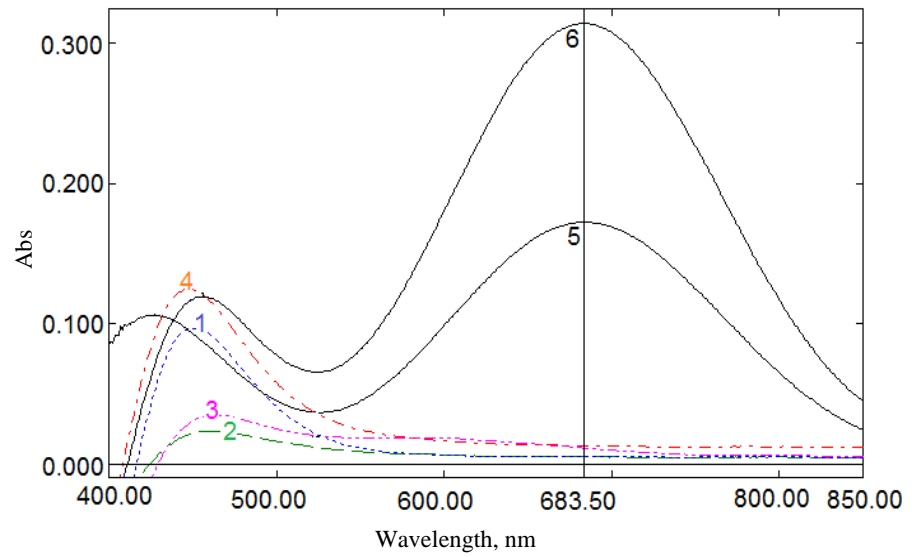

Figure 4. Absorption spectra (obtained against reagent blank) at $10 \mathrm{~mL}$ dilution of aqueous solution of glibenclamide, glimepiride, glipizide, gliclazide (1-4), 82.81 and $165.62 \mu \mathrm{g}$ of MHCl (5-6), added to $2.0 \mathrm{~mL}$ of $1.0 \mathrm{~mol} \mathrm{~L}^{-1}$ of $\mathrm{NaOH}, 1.0 \mathrm{~mL}$ of $1 \% \mathrm{NaOCl}$, and $2.0 \mathrm{~mL}$ of $5.0 \times 10^{-3} \mathrm{~mol} \mathrm{~L}^{-1}$ of SNP.

\section{Detection of metformin in synthetic pharmaceutical formulations}

Detection of metformin in presence of gliclazide, glibenclamide, glimepiride or glipizide was carried out by forming their mixture with metformin. A single tablet of gliclazide (80 $\mathrm{mg}$ ), glibenclamide (5 mg), glimepiride (1 mg) or glipizide (5 mg) was powered and dissolved in $25 \mathrm{~mL}$ of $95 \%$ ethanol. The solution was filtered through Whatman filter paper 42. Later $5.0 \mathrm{~mL}$ filtrate of gliclazide, glibenclamide, glimepiride or glipizide tablet was added to pure metformin hydrochloride solution and diluted to $100 \mathrm{~mL}$ with distilled water so 
that final solution was contain $20.0 \mu \mathrm{g} \mathrm{mL} \mathrm{m}^{-1}$ of metformin with other constituent. This solution was then subjected for detection of metformin by obtaining the absorption spectra against distilled water.

The result of detection of metformin in presence of gliclazide is shown in Figure 5, which illustrate that, though the alcoholic solution of gliclazide does not generate green color on reaction with sodium nitroprusside, its presence with metformin still decreases formation of green color complex. The shift in absorption maxima to the shorter wavelength and decrease in color intensity of the product indicates that gliclazide generates colorless product on reaction with these reagents. The result of detection of metformin in presence of glibenclamide, glimepiride and glipizide are reported in Figure 6, Figure 7 and Figure 8 respectively. These results interpret that, alcoholic solutions of glibenclamide, glimepiride and glipizide in presence of metformin does not affects the green color intensity of the product.

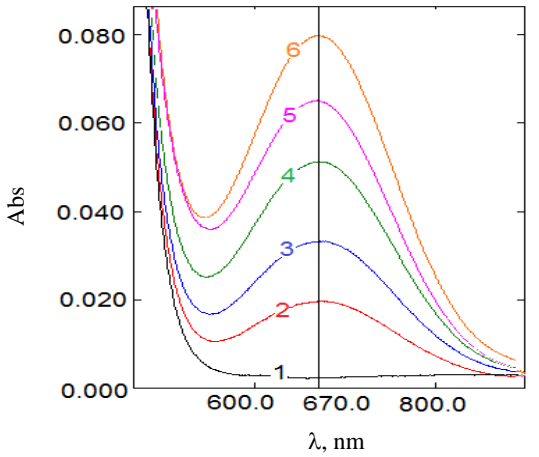

Figure 5

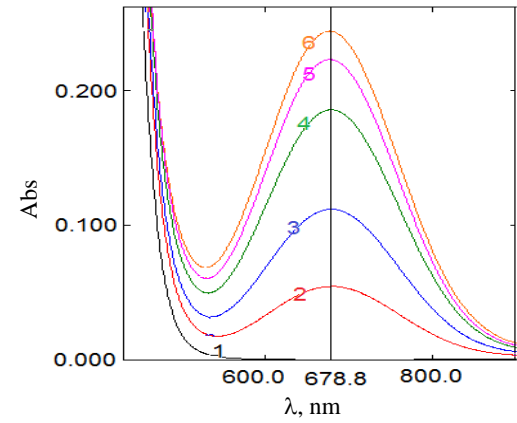

Figure 7

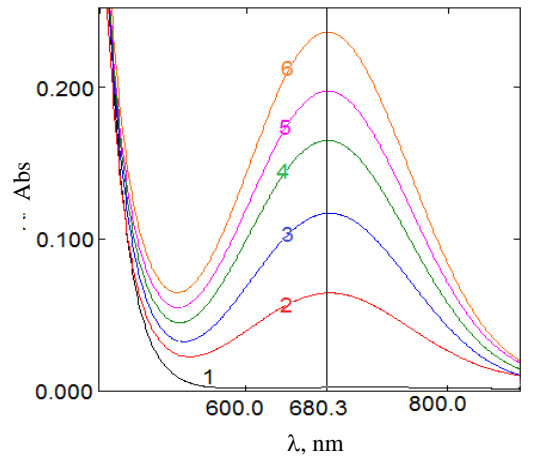

Figure 6

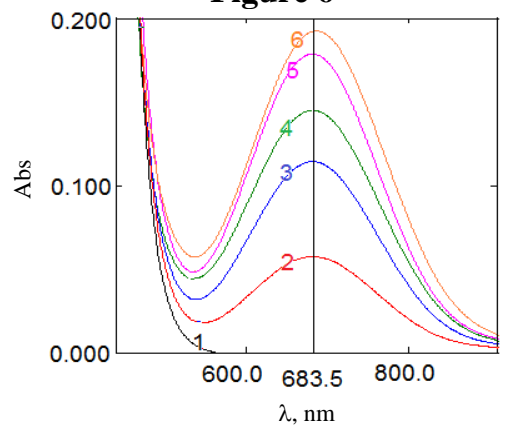

Figure 8

Figure 5-8. Absorption spectra of 0.0, 20.0, 40.0, 60.0, 80.0 and $100.0 \mu \mathrm{g}$ of $\mathrm{MHCl}(1-6)$ spiked with gliclazide (Figure 5), glibenclamide (Figure 6), glimepiride (Figure 7) and glipizide (Figure 8) respectively.

In addition the detection of metformin was also carried out with the mixture of gliclazide, glibenclamide, glimepiride and glipizide. An aliquots of $1.0 \mathrm{~mL}$ alcoholic filtrate of each tablet (prepared as above) were added to pure $\mathrm{MHCl}$ solution and diluted to $80 \mathrm{~mL}$ with distilled water so that final solution was containing $20.0 \mu \mathrm{g} \mathrm{ml}^{-1}$ of metformin. Different aliquots of this diluted solution were subjected for detection of metformin. The result for detection of metformin in presence of all these four constituents is shown in Figure 9, 
which illustrates that the mixture of gliclazide, glibenclamide, glimepiride and glipizide does not affect the intensity green color and the absorption maxima of the product. This could be probably due to low concentration of gliclazide in this mixture.

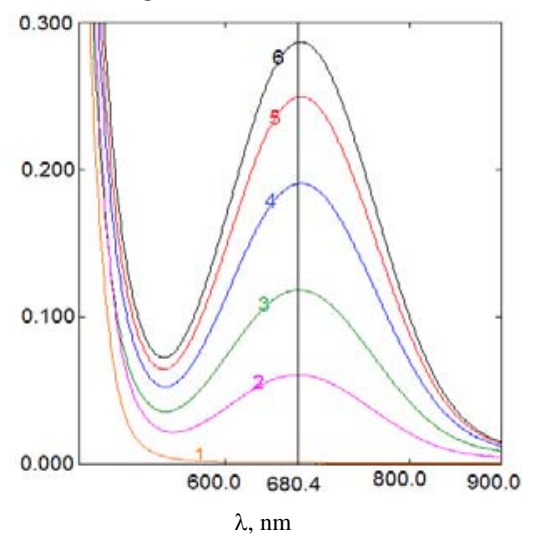

Figure 9. Absorption spectra (obtained against distilled water) at $10 \mathrm{~mL}$ dilution of 0.0 , 20.00, 40.00, 60.00, 80.00 and $100.0 \mu \mathrm{g}$ of $\mathrm{MHCl}(1-6)$ spiked with the mixture of gliclazide, glibenclamide, glimepiride and glipizide.

\section{Conclusion}

The proposed spectrophotometric procedure is simple, cost-effective, time saving and permits direct identification of metformin in the aqueous solution containing glibenclamide, glimepiride, glipizide and gliclazide. Sodium nitroprusside is able to reacts in basic medium at room temperatures with the oxidized product of the metformin to produce green colored 1 , 3 dinitrosyl- $N$ '-(iminomethyl)- $N$, $N$-dimethyl formamidine complex. Consequently, the suggested method is selective and free from interferences of the common excipients and additives present in pharmaceutical dosage forms. Moreover, it exhibits the advantage of utilization of a single step reaction and sensitive for spectrophotometric detection of metformin upto $16.56 \mu \mathrm{g}$. The detection of metformin is also feasible without spectrophotometer when concentration of metformin greater than and equal to $49.68 \mu \mathrm{g}$ in $10 \mathrm{~mL}$ solution. The method should be useful for routine analytical and quality control identification of the metformin. The green colored 1, 3 dinitrosyl- $N$ '-(iminomethyl)- $N, N$ dimethyl formamidine complex of the oxidized product of metformin was obtained only in strong basic solution and has dissociative nature in aqueous medium. Consequently it can also be concluded that the procedure is not suitable for quantitative determination of metformin in aqueous medium.

\section{Acknowledgement}

Authors have a deep sense of thankfulness and obligation to the Managing Committee of Maratha Vidya Prasarak Samaj, Nashik for providing the necessary infrastructure and instrumentations. Authors thank to the University Grant Commission (UGC) and Board of College and University Development (BCUD), University of Pune, Pune for providing the sizable funds under the minor research projects.

\section{References}

1. British Pharmacopoeia. Vol II, Cambridge University Press, Cambridge, 1988. 
2. Bailey C J and Path M R C and Robert C Turner New Engl J Med., 1996, 334(9), 574-579.

3. Arayne M S, Sultana N, Zuberi M H and Siddiqui F A, Indian J Pharm Sci., 2009, 71, 331-335; DOI:10.4103/0250-474X.56022

4. Hassan S S M, Mahmoud W H, Elmosallamy M A and Othman A H, Anal Chim Acta 1999, 378, 299-311.

5. $\quad$ Ahmad N R and Omar F K, Iraqi National J Chem., 2012, 46, 161-170.

6. $\quad$ Ahmad N R, Iraqi J Pharm., 2012, 12, 75-85.

7. Ashour S and Kabbani R, Anal Lett., 2003, 36(2), 361-370; DOI:10.1081/AL120017696

8. Onal Armagan, European J Med Chem., 2009, 44(12), 4998-5005;

DOI:10.1016/j.ejmech.2009.09.003

9. Thomas A B and Patil S D, Der Pharma Chemica, 2011, 3(3), 271-276.

10. Rucki R, In: K. Florey (Ed.), Analytical Profile of Drug Substances, Vol. 6, Academic Press, New York, 1977, pp. 488-513.

11. Leeuwenkamp O R, Van Benneekom W P and Bult A, In: Florey K, (Ed.), Analytical Profile of Drug Substances, Vol. 15, Academic Press, New York, 1986, pp. 782-789.

12. Askal H F, Refaat I H, Darwish I A and Marzouq M A, Spectrochimica Acta Part-A: Mole Biomole Spectr., 2008, 69, 1287-1291; DOI:10.1016/j.saa.2007.07.031

13. Yanyan Zhan, Yan Zhang, Quanmin Li and Xinzhen Du, J Anal Chem., 2011, 66, 215-220.

14. Quan-min Li and Lin-xiao Gao, Anal Lett., 2008, 41(14), 2595-2607; DOI:10.1080/00032710802363354

15. Gurupadayya B M, Trinath M N and Shilpa K, Indian J Chem Technol., 2013, 20, 111-115.

16. Hua Zhang, Ling Li Wu, Quan Min Li and Xin Zhen Du, Chinese Chem Lett., 2008, 19(12), 1470-1474; DOI:10.1016/j.cclet.2008.09.014

17. Zenovia Moldovan and Hassan Y Aboul-Enein, Instru Sci Technol., 2011, 39(2), 135148; DOI:10.1080/10739149.2010.545851

18. Bhashir N, Shah S W H, Bangesh M and Riazullah, J Sci Indu Res., 2011, 70, 51-54

19. Yan-Yan Zhan, Yan Zhang, Quan-Min Li and Xin-Zhen Du, J Chine Chem Soc., 2010, 57(2), 230-235; DOI:10.1002/jccs.201000035

20. $\quad$ Rele R V, Sawant S A and Warkar C B, Int J Chem Tech Res., 2010, 2(4), 2173-2176.

21. Kalyanaramu B and Raghubabu K, Der Pharma Chemica, 2011, 3(1), 223-228.

22. Kalyanaramu B, Raghubabu K and Vamsikumar Y, J Chem Pharm Res., 2011, 3(2), 863-869.

23. Sharma R, Rathore S S, Sharma P and Sharma A, J Chem Pharmace Res., 2009, 1(1), 321-328.

24. El-Walily A F M, Abdine H H, Razak O A and Zamel S, J Pharm Biomed Anal., 2000, 22(6), 887-897; DOI:10.1016/S0731-7085(99)00290-3

25. Shah J, Rasul J M and Rehman F, J Chil Chem Soc., 2008, 53, 1605-1608.

26. Kasim Y.R, Batool B I and Hayfa M.J, Raf J Sci., 2011, 22(3), 119-128.

27. European Pharmacopoeia 5.0, Monographs M, pp. 2003-2004 and European Pharmacopoeia 7.0, Monographs M, pp.2458-2459.

28. Vilchez J L, Blanc R, Avidad R and Navalon A, J Pharma Biomed Anal., 1995, 13(9), 1119-1125; DOI:10.1016/0731-7085(95)01537-U

29. Drug Today, India, Vol. II, Oct.-Dec.2011, pp.1079-1086. 